\title{
Resonance and Parametric Analysis of Planar Broad-Wall Longitudinal Slot Array Antennas
}

\author{
Rintu Kumar Gayen and Sushrut Das
}

\begin{abstract}
This paper presents, method of moments based analysis of broad-wall longitudinal slots array antenna using Multiple Cavity Modeling Technique (MCMT). Theoretical data for reflection coefficient, transmission coefficient, resonance length and resonance conductance have been obtained for two slots in two different waveguide. The theoretical data have been compared with Ansoft HFSS's simulated data to validate the proposed method. The excellent agreement obtained between the results demonstrates that the proposed method is able to accurately and efficiently solve complex reflection coefficients and transmission coefficients for different slot parameters.
\end{abstract}

Keywords--- Waveguides, Slot Array Antennas, MCMT, Moment Method, Reflection Coefficients, Transmission Coefficients, Normalized Admittance and Resonance

\section{INTRODUCTION}

STUDIES on waveguide broad-wall longitudinal slot Santennas date back before World War II. Till then a number of workers have carried out considerable investigations on the admittance properties of the structure and a detail review of it will be a literature of its own. A brief survey of these literatures has been provided in [1]. However most of these analyses were carried out for a single slot element. Few literatures are also available on slot array [2, 3, $4,5,6,7,8,9,10,11,12,13,14]$.

In this paper we have analyzed a two element planar broad-wall longitudinal slots array antenna based on Multiple Cavity Modeling Technique (MCMT) [15]. The theoretical data have been compared with the Ansoft HFSS's simulated data to validate the proposed method. The excellent agreement between the results demonstrates that the proposed method is able to accurately and efficiently solve complex reflection coefficients and transmission coefficients for different slot parameters.

\section{PROBLEM Formulation}

The 3D view of a planar two element broad-wall longitudinal slot antenna is shown in figure 1 whereas the top view of the waveguide slot antenna is shown in figure 2 . The

Rintu Kumar Gayen, Senior Research Fellow, Department of Electronics Engineering, Indian School of Mines - Dhanbad, Dhanbad, Jharkhand826004, India.E-mail:rintukrgayen@gmail.com

Sushrut Das, Assistant Professor, Department of Electronics Engineering, Indian School of Mines - Dhanbad, Dhanbad, Jharkhand826004, India.E-mail:sushrut_das@yahoo.com corresponding cavity modeling and details of magnetic current at the apertures is shown in figure 3 .

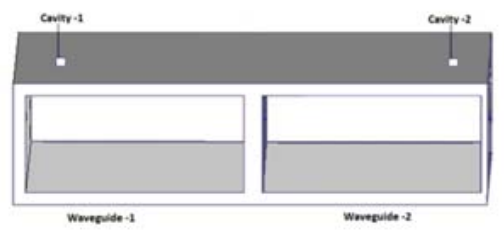

Figure 1: Three Dimensional View of a Two Element Planer Waveguide Slots Antenna

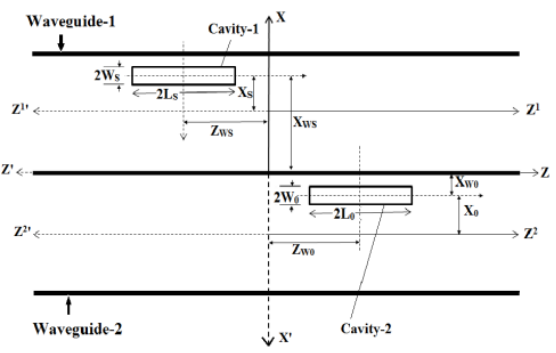

Figure 2: Top Views of the Proposed Waveguide Slot Antenna

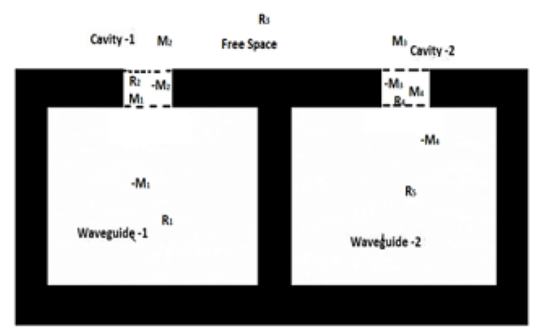

Figure 3: Details of Different Regions and Magnetic Currents at the Apertures of a Two Element Planar Waveguide Slot Antenna

The electric field at the slot may be assumed to be Xdirected and can be expressed in terms of a sum of weighted sinusoidal basis functions, $e_{p, z}^{i}$ defined over the entire length of the slot as follows:

$$
\vec{E}^{i}\left(x^{\prime}, y^{\prime}, z^{\prime}\right)=\hat{u}_{x} \sum_{p=1}^{M} E_{p, z}^{i} e_{p, z}^{i}
$$

Where $e_{p, z}^{i}$ is defined as: 


$$
\begin{aligned}
& e_{p, z}^{i}\left(x^{\prime}, y^{\prime}, z^{\prime}\right)= \\
& \left\{\begin{array}{cc}
\sin \left\{\frac{p \pi}{2 L_{S}}\left(z^{\prime}-z_{w S}+L_{S}\right)\right\} \delta\left(y^{\prime}-b\right) & \text { On aperture " } i " \\
0 & \text { Elsewhere }
\end{array}\right.
\end{aligned}
$$

Where $2 \mathrm{Ls}$ is the slot length, $2 \mathrm{Ws}$ is the slot width, $2 \mathrm{Z}_{\mathrm{Ws}}$ is the distance between the slots and $2 \mathrm{~b}$ is the guide height. With the given electric field distribution the magnetic currents can be obtained using equivalence principle.

At the region of slot, the tangential components of the magnetic field should be identical. This results in the fallowing boundary condition.

$$
\begin{aligned}
& H_{Z}^{w v g 1}\left(M_{Z}^{1}\right)+H_{Z}^{\operatorname{cav} 1}\left(M_{Z}^{1}\right)-H_{Z}^{\operatorname{cav} 1}\left(M_{Z}^{2}\right)=H_{Z}^{i n c} \\
& -H_{Z}^{\operatorname{cav} 1}\left(M_{Z}^{1}\right)+H_{Z}^{\operatorname{cav} 1}\left(M_{Z}^{2}\right)+H_{Z}^{\text {ext }}\left(M_{Z}^{2}\right)+ \\
& H_{Z}^{\text {ext }}\left(M_{Z}^{3}\right)=0 \\
& H_{Z}^{\text {ext }}\left(M_{Z}^{2}\right)+H_{Z}^{\text {ext }}\left(M_{Z}^{3}\right)+H_{Z}^{\operatorname{cav} 2}\left(M_{Z}^{3}\right)- \\
& H_{Z}^{\operatorname{cav} 2}\left(M_{Z}^{4}\right)=0 \\
& -H_{Z}^{\operatorname{cav} 2}\left(M_{Z}^{3}\right)+H_{Z}^{\operatorname{cav} 2}\left(M_{Z}^{4}\right)+H_{Z}^{w v g} 2\left(M_{Z}^{4}\right)=0
\end{aligned}
$$

The Green's function, derived by solving the Helmholtz equation for the electric vector potential for unit magnetic current source is used for obtaining the magnetic field spread inside the cavity region. The scattered field inside the waveguide due to slots in the broad wall of the waveguide also has been derived using the Green's function for the electric potential for such a slot [1]. From the field existing at the apertures fed by the waveguide, the radiated field can be derived using plane wave spectrum approach. The radiated field is obtained by expanding the spherical waves in terms of plane wave spectrum in the vector potential formulation [1].

The field components are given by:

$$
\begin{aligned}
& H_{Z}^{e x t}\left(M_{Z}^{i}\right)=-\frac{W_{S} L_{S}}{\pi^{2} k \eta} \sum_{p=1}^{M} E_{p, Z}^{i} \times \\
& \int_{-\infty-\infty}^{\infty} \int^{\infty} \frac{k^{2}-k_{X}^{2}}{\left(k^{2}-k_{X}^{2}-k_{Z}^{2}\right)^{1 / 2} \operatorname{Sinc}\left(k_{X} W_{S}\right) \times} \\
& e^{-j\left(k_{X} X_{W S}+k_{Z} Z_{W S}\right)} \frac{\left\{\begin{array}{l}
j \sin \left(k_{Z} L_{S}\right) \text { if } p \text { is even } \\
\cos \left(k_{Z} L_{S}\right) \text { if } p \text { odd }
\end{array}\right.}{\frac{p \pi}{2}\left\{1-\left(\frac{2 L_{S} k_{Z}}{p \pi}\right)^{2}\right\}} \\
& e^{j\left(k_{Z^{\prime}}+k_{X} X^{\prime}\right)_{d k_{Z}} d k_{X}}
\end{aligned}
$$

$$
\begin{aligned}
& H_{Z}^{w v g}\left(M_{Z}^{i}\right)=\sum_{p=1}^{M} E_{p, Z}^{i} \sum_{m=0}^{\infty} \sum_{n=0}^{\infty} \frac{j \varepsilon_{m} \varepsilon_{n} W_{S}}{2 k \eta \gamma_{m n}^{2} a b} \frac{\cos (n \pi)}{1+S^{2}(p)} \times \\
& \cos \left\{\frac{m \pi}{2 a}\left(x_{S}+a\right)\right\} \sin c\left(\frac{m \pi}{2 a} W_{S}\right) \times \\
& {\left[\begin{array}{l}
\left\{k^{2}-\left(\frac{p \pi}{2 L_{S}}\right)\right\} \sin \left\{\frac{p \pi}{2 L_{S}}\left(z+L_{S}\right)\right\}+\left(k^{2}+\gamma_{m n}^{2}\right) \times \\
S(p) e^{-\gamma_{m n} L_{S}}\left\{\begin{array}{l}
-\sinh \left(\gamma_{m n} z\right) \text { if } p \text { even } \\
\cosh \left(\gamma_{m n} z\right) \text { if } p \text { odd }
\end{array}\right\}
\end{array}\right] \times} \\
& \cos \left\{\frac{m \pi}{2 a}(x+a)\right\} \cos \left\{\frac{n \pi}{2 b}(y+b)\right\} \\
& H_{Z}^{i n c}=-j \sin \left(\frac{\pi x}{2 a}\right) e^{-j \beta z} \\
& H_{Z}^{c a v}\left(M_{Z}^{i}\right)=\frac{j \omega \varepsilon}{k^{2}} \sum_{p=1}^{M} E_{p, z}^{i} \sum_{m=p=1}^{\infty}\left\{k^{2}-\left(\frac{m \pi}{2 L_{S}}\right)^{2}\right\} \times \\
& \sin \left\{\frac{m \pi}{2 L_{S}}\left(z+L_{S}\right)\right\} \cos \left\{\frac{n \pi}{2 W_{S}}\left(x+W_{S}\right)\right\} \frac{(-1)}{\Gamma_{m n} \sin \left\{2 \Gamma_{m n}\right\}} \times \\
& \left\{\begin{array}{l}
\left(\begin{array}{l}
\cos \left\{\Gamma_{m n}(y-t)\right\} \cos \left\{\Gamma_{m n}\left(y^{\prime}+t\right)\right\} y>y^{\prime} \\
\cos \left\{\Gamma_{m n}\left(y^{\prime}-t\right)\right\} \cos \left\{\Gamma_{m n}(y+t)\right\} y>y^{\prime}
\end{array}\right) \text { for } m=p \text { and } n=0 \\
0 \quad \text { otherwise }
\end{array}\right.
\end{aligned}
$$

Where 2a is the guide width, $2 \mathrm{t}$ is the slot / waveguide wall thickness, $x_{s}$ is the slot offset from the center of the waveguide and

$$
S(p)=p \pi /\left(2 L_{S} \gamma_{m n}\right)
$$

Rests of the symbols have their usual meaning.

The method of moments is applied with Galerkin's specialization [16] to obtain 2M different equations from the boundary conditions to enable determination of the $E_{p, z}^{i}$. The weighting functions $w_{q, z}^{l}(x, y, z)$ are defined as follows:

$$
\begin{aligned}
& w_{q, z}^{l}(x, y, z)= \\
& \left\{\sin \left\{\frac{q \pi}{2 L_{0}}\left(z-z_{w 0}+L_{0}\right)\right\} \delta(y-b)\right. \text { On aperture "l" }
\end{aligned}
$$

for all $q(q=1,2,3, \ldots . . . ., M)$. After taking moment of each of the terms in boundary conditions (1) - (4), with $w_{q, z}^{l}$, we obtain a set of simultaneous equations which upon solving gives the unknown basis coefficients. Here we have assumed that weighting function is defines over a slot having slot length $2 \mathrm{~L}_{0}$, slot width $2 \mathrm{~W}_{0}$, and $2 \mathrm{Z}_{\mathrm{W} 0}$ is the distance between 
the slots. The (p, q)th elements of the moment matrices can be derived as follows:

$$
\begin{aligned}
& \left\langle H_{Z}{ }^{i n c}, w_{q}^{i, x}\right\rangle=j \frac{2 \pi W_{S} q}{L_{S}} \sin \left(\frac{\pi x_{S}}{2 a}\right) \operatorname{sinc}\left(\frac{\pi W_{S}}{2 a}\right) \times \\
& e^{-j \beta\left(z_{W S}\right)} \frac{\left\{\begin{array}{c}
\cos \left(\beta L_{S}\right) \text { for } q \text { odd } \\
j \sin \left(\beta L_{S}\right) \text { for } q \text { even }
\end{array}\right\}}{\left\{\beta^{2}-\left(\frac{q \pi}{2 L_{S}}\right)^{2}\right\}} \\
& \left\langle H_{Z}^{c a v}, w_{q}^{x}\right\rangle=-j \frac{2 \omega \varepsilon L_{s} W_{S}}{k^{2}} \sum_{m=p=1}^{\infty}\left\{k^{2}-\left(\frac{m \pi}{2 L_{S}}\right)^{2}\right\} \times \\
& \frac{(-1)}{\Gamma_{m n} \sin \left\{2 \Gamma_{m n} t\right\}} \times \\
& \left\{\begin{array}{l}
\left(\begin{array}{l}
\cos \left\{\Gamma_{m n}(y-t)\right\} \cos \left\{\Gamma_{m n}\left(y_{0}+t\right)\right\} \\
\cos \left\{\Gamma_{m n}\left(y_{0}-t\right)\right\} \cos \left\{\Gamma_{m n}(y+t)\right\}
\end{array}\right)\left(\begin{array}{l}
\text { for } \mathrm{m}=\mathrm{p}=\mathrm{q} \\
\text { and } \mathrm{n}=0
\end{array}\right. \\
0 \quad \text { otherwise }
\end{array}\right. \\
& \left\langle H_{Z}^{\text {ext }}\left(M_{z}^{3}\right), w_{q}^{2}\right\rangle_{\substack{\text { visible } \\
\text { region }}}=-\frac{16 W_{S} W_{0} L_{S} L_{0}}{\lambda^{2} \eta} \times \\
& \int_{\theta=0}^{\pi / 2} \int_{\phi=0}^{2 \pi}\left(1-\sin ^{2} \theta \cos ^{2} \phi\right) \sin c\left(k \sin \theta \sin \phi W_{S}\right) \times \\
& \sin c\left(k \sin \theta \sin \phi W_{0}\right) e^{j\left(k x_{w S} \sin \theta \sin \phi+k z_{w S} \sin \theta \cos \phi\right)} \times \\
& e^{-j\left(k x_{w 0} \sin \theta \sin \phi+k z_{w 0} \sin \theta \cos \phi\right)} \times \\
& \left\{\left(\begin{array}{c}
\sin \left(k L_{S} \sin \theta \cos \phi\right) \times \\
\sin \left(k L_{0} \sin \theta \cos \phi\right)
\end{array}\right) \text { if } p, q\right. \text { both even } \\
& \left\{\left(\begin{array}{c}
\cos \left(k L_{S} \sin \theta \cos \phi\right) \times \\
\cos \left(k L_{0} \sin \theta \cos \phi\right)
\end{array}\right) \text { if } p, q\right. \text { both odd } \\
& \frac{p \pi}{2}\left\{1-\left(\frac{2 L_{S} k \sin \theta \cos \phi}{p \pi}\right)^{2}\right\} \times \\
& \frac{q \pi}{2}\left\{1-\left(\frac{2 L_{0} k \sin \theta \cos \phi}{q \pi}\right)^{2}\right\}
\end{aligned}
$$

$\left\langle H_{Z}^{\text {ext }}\left(M_{Z}^{3}\right), w_{q}^{2}\right\rangle_{\substack{\text { invisible } \\ \text { region }}}=-\frac{16 W_{s} W_{0} L_{S} L_{0}}{\lambda^{2} \eta} \times$ $\int_{\theta=0}^{\pi / 2} \int_{\phi=0}^{2 \pi}\left(1-\cosh ^{2} \theta \cos ^{2} \phi\right) \sin c\left(k \cosh \theta \sin \phi W_{S}\right) \times$ $\sin c\left(k \cosh \theta \sin \phi W_{0}\right) e^{j\left(k x_{w S} \cosh \theta \sin \phi+k z_{w S} \cosh \theta \cos \phi\right)} \times$ $e^{-j\left(k x_{w 0} \cosh \theta \sin \phi+k z_{w 0} \cosh \theta \cos \phi\right)} \times$ $\left\{\left(\begin{array}{c}\sin \left(k L_{S} \cosh \theta \cos \phi\right) \times \\ \sin \left(k L_{0} \cosh \theta \cos \phi\right)\end{array}\right)\right.$ for $p, q$ both even $\left(\begin{array}{c}\cos \left(k L_{S} \cosh \theta \cos \phi\right) \times \\ \cos \left(k L_{0} \cosh \theta \cos \phi\right)\end{array}\right)$ for $p, q$ both odd $\frac{p \pi}{2}\left\{1-\left(\frac{2 L_{S} k \cosh \theta \cos \phi}{p \pi}\right)^{2}\right\} \times \cosh \theta d \theta d \phi$ $\frac{q \pi}{2}\left\{1-\left(\frac{2 L_{0} k \cosh \theta \cos \phi}{q \pi}\right)^{2}\right\}$ $\left\langle H_{Z}^{\text {ext }}\left(M^{i}\right), w_{q}^{i}\right\rangle_{\substack{\text { visible } \\ \text { region }}}=-\frac{16 W_{S}^{2} L_{S}^{2}}{\lambda^{2} \eta} \times$ $\int_{\theta=0}^{\pi / 2} \int_{\phi=0}^{2 \pi}\left(1-\sin ^{2} \theta \cos ^{2} \phi\right) \sin c^{2}\left(W_{s} k \sin \theta \sin \phi\right) \times$ $\frac{\left\{\begin{array}{c}\sin ^{2}\left(L_{S} k \sin \theta \cos \phi\right) \text { for p,q both even } \\ \cos ^{2}\left(L_{S} k \sin \theta \cos \phi\right) \text { for p,q both odd } \\ 0 \quad \text { otherwise }\end{array}\right\}}{\frac{\mathrm{p} \pi}{2} \frac{q \pi}{2}\left\{1-\left(\frac{2 L_{S} k \sin \theta \cos \phi}{p \pi}\right)\right.} \sin \theta d \theta d \phi$ $\left\{1-\left(\frac{2 L_{S} k \sin \theta \cos \phi}{q \pi}\right)^{2}\right\}$ 


$$
\begin{aligned}
& \left\langle H_{Z}^{e x t}\left(M^{i}\right), w_{q}^{i}\right\rangle_{\substack{\text { invisible } \\
\text { region }}}=-\cosh \theta j \frac{16 W_{S}{ }^{2} L_{S}{ }^{2}}{\lambda^{2} \eta} \times \\
& \int_{\theta=0}^{\pi / 2} \int_{\phi=0}^{2 \pi}\left(1-\cosh ^{2} \theta \cos ^{2} \phi\right) \times \\
& \operatorname{sinc}^{2}\left(W_{S} k \cosh \theta \sin \phi\right) \times \\
& \frac{\left\{\begin{array}{c}
\sin ^{2}\left(L_{S} k \cosh \theta \cos \phi\right) \text { for p,q both even } \\
\cos ^{2}\left(L_{S} k \cosh \theta \cos \phi\right) \text { for p,q both odd } \\
0 \quad \text { otherwise }
\end{array}\right\}}{\frac{\mathrm{p} \pi}{2} \frac{q \pi}{2}\left\{1-\left(\frac{2 L_{S} k \cosh \theta \cos \phi}{p \pi}\right)^{2}\right\}} d \theta d \phi \\
& \left\{1-\left(\frac{2 L_{s} k \cosh \theta \cos \phi}{q \pi}\right)^{2}\right\} \\
& \left\langle H_{z}^{w v g}, w_{p}^{X}\right\rangle=-\sum_{m=0}^{\infty} \sum_{n=0}^{\infty} j \frac{\varepsilon_{m} \varepsilon_{n} W_{s}^{2}}{k \eta \gamma_{m n}^{2} a_{1} b_{1}} \times \\
& \frac{1}{1+S^{2}(p)} \cos ^{2}\left\{\frac{m \pi}{2 a_{1}}\left(x_{S}+a_{1}\right)\right\} \sin c^{2}\left\{\frac{m \pi}{2 a_{1}} W_{S}\right\} \times \\
& {\left[\begin{array}{l}
\left\{k^{2}-\left(\frac{p \pi}{2 L_{S}}\right)^{2}\right\} \delta_{p q} L_{S}+ \\
\frac{2 S(p) S(q)\left(k^{2}+\gamma_{m n}^{2}\right)}{\gamma_{m n}\left(1+S^{2}(q)\right)} e^{-\gamma_{m n} L_{1}} \times \\
\left\{\begin{array}{l}
\sinh \left(\gamma_{m n} L_{S}\right) \text { for } p, q \text { both even } \\
\cosh \left(\gamma_{m n} L_{s}\right) \text { for } p, q \text { both odd } \\
0
\end{array}\right\}
\end{array}\right]}
\end{aligned}
$$

The expression for the reflection coefficients $\Gamma$ and transmission coefficients $\mathrm{T}$ at the $\mathrm{z}=0$ plane are obtained as:

$$
\begin{gathered}
\Gamma=\left.\frac{H_{Z}^{-}}{H_{Z}^{\text {inc }}}\right|_{Z=0}=\frac{\pi^{2} W_{S}}{4 a^{3} b k \beta^{2}} \sin \left(\frac{\pi x_{S}}{2 a}\right) \sin c\left(\frac{\pi W_{S}}{2 a}\right) \times \\
\sum_{p=1}^{M} E_{p, Z}^{1} \frac{s(p)}{1+s^{2}(p)}\left\{\begin{array}{l}
\cos \left(\beta L_{S}\right) \text { for } p \text { odd } \\
j \sin \left(\beta L_{S}\right) \text { for } p \text { even }
\end{array}\right\} \\
\mathrm{T}=\frac{H_{Z}^{+}+H_{Z}^{\text {inc }}}{H_{Z}^{\text {inc }}}=1+\frac{\pi^{2} W_{S}}{4 a^{3} b k \beta^{2}} \sin \left(\frac{\pi x_{S}}{2 a}\right) \sin c\left(\frac{\pi W_{S}}{2 a}\right) \times \\
\sum_{p=1}^{M} E_{p, Z}^{1} \frac{s(p)}{1+s^{2}(p)}\left\{\begin{array}{l}
\cos \left(\beta L_{S}\right) \text { for } p \text { odd } \\
j \sin \left(\beta L_{S}\right) \text { for } p \text { even }
\end{array}\right\}
\end{gathered}
$$

Where $2 \mathrm{~L}_{0}$ and $2 \mathrm{~W}_{0}$ are the length and width of the slot on which weighting function is defined. The admittance for the shunt network models are obtained from the $\mathrm{Y}$ using the following relations [11].

$$
Y=-2 \Gamma /(1+\Gamma) .
$$

\section{NUMERICAL RESULTS}

On the basis of the formulation, MATLAB codes have been written to compute the reflection coefficients and transmission coefficients of the structures.

The magnitude of the $S$ - parameters of the structure for slots length $=16 \mathrm{~mm}$, width $=1 \mathrm{~mm}$, thickness $=1.27 \mathrm{~mm}$, Xs $=-8.43 \mathrm{~mm}, \mathrm{X}_{0}=-8.43 \mathrm{~mm},\left|\mathrm{Z}_{\mathrm{Ws}}-\mathrm{Z}_{\mathrm{W} 0}\right|=0 \mathrm{~mm}$ and $\mid \mathrm{X}_{\mathrm{Ws}}-$ $\mathrm{X}_{\mathrm{Wo}} \mathrm{l}=24.13 \mathrm{~mm}$ milled as a waveguide with $2 \mathrm{a}=22.86 \mathrm{~mm}$, $2 \mathrm{~b}=10.16 \mathrm{~mm}$ have been obtained and compared with HFSS data over a frequency range $8 \mathrm{GHz}$ to $12 \mathrm{GHz}$. The theoretical and HFSS data results have been plotted in Figure 4.

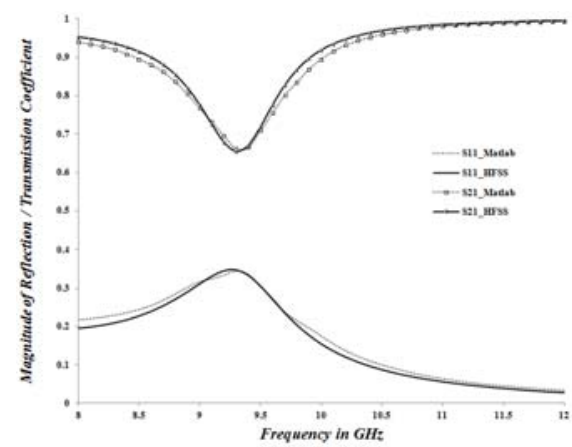

Figure 4: Comparison of Theoretical Data with HFSS Data for Two Broad wall Longitudinal Slots Antenna System

The variation of the complex $\mathrm{S}$ - parameters for slots with length $=16 \mathrm{~mm}$, width $=1 \mathrm{~mm}$, thickness $=1.27 \mathrm{~mm}$, width $=$ $1 \mathrm{~mm}, \mathrm{X}_{\mathrm{S}}=4 \mathrm{~mm}, \mathrm{X}_{0}=-4 \mathrm{~mm},\left|\mathrm{X}_{\mathrm{Ws}}-\mathrm{X}_{\mathrm{Wo}}\right|=24.13 \mathrm{~mm}$, $32.13 \mathrm{~mm}, 48.26 \mathrm{~mm}, 56.26 \mathrm{~mm}$, and $\left|Z_{\mathrm{ws}}-\mathrm{Z}_{\mathrm{W} 0}\right|=0 \mathrm{~mm}$ milled as a waveguide with $2 \mathrm{a}=22.86 \mathrm{~mm}, 2 \mathrm{~b}=10.16 \mathrm{~mm}$ are plotted with frequency in figure 5 and figure 6 respectively.

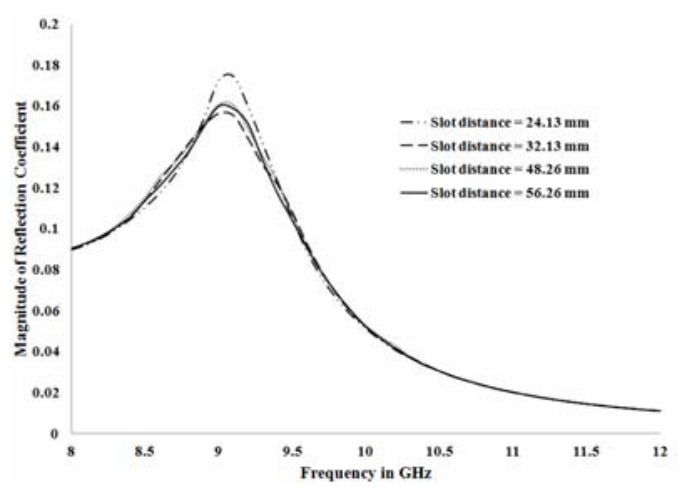




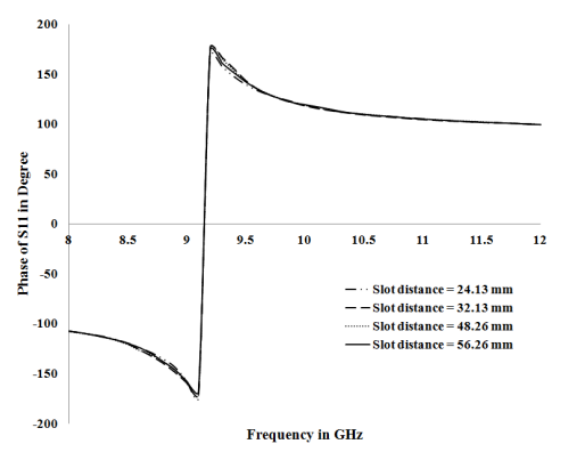

Figure 5: Variation of Complex Reflection Coefficients with Frequency for Two Broad Wall Longitudinal Slots Antenna System with Different Slot Distance

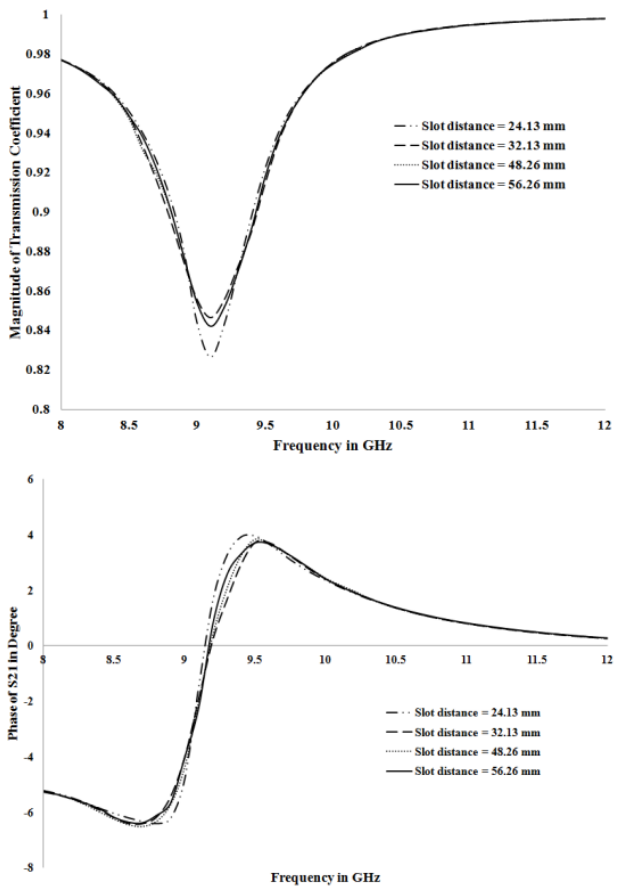

Figure 6: Variation of Complex Transmission Coefficients with Frequency for Two Broad Wall Longitudinal Slots Antenna System with Different Slot Distance

The variation of the complex S - parameters for slots with for different slot lengths $=16.6667 \mathrm{~mm}, 15.0001 \mathrm{~mm}, 13.6364$ $\mathrm{mm}$, thickness $=1.27 \mathrm{~mm}$, width $=1 \mathrm{~mm}, \mathrm{X}_{\mathrm{S}}=4 \mathrm{~mm}, \mathrm{X}_{0}=-4$ $\mathrm{mm},\left|\mathrm{X}_{\mathrm{Ws}}-\mathrm{X}_{\mathrm{Wo}}\right|=24.13 \mathrm{~mm}$ and $\left|\mathrm{Z}_{\mathrm{Ws}}-\mathrm{Z}_{\mathrm{Wo}}\right|=0 \mathrm{~mm}$ milled as a waveguide with $2 \mathrm{a}=22.86 \mathrm{~mm}, 2 \mathrm{~b}=10.16 \mathrm{~mm}$ are plotted with frequency in figure 7 and figure 8 respectively.

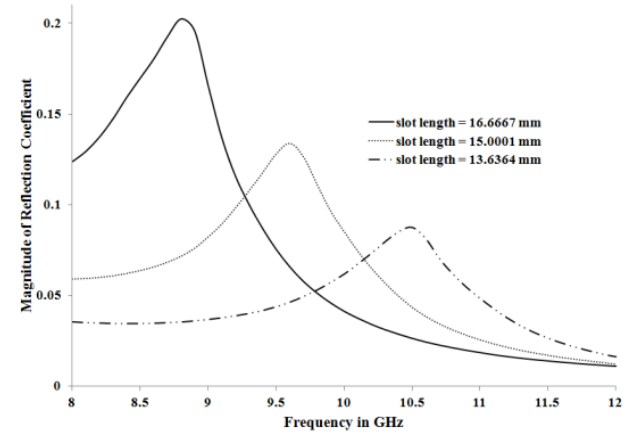

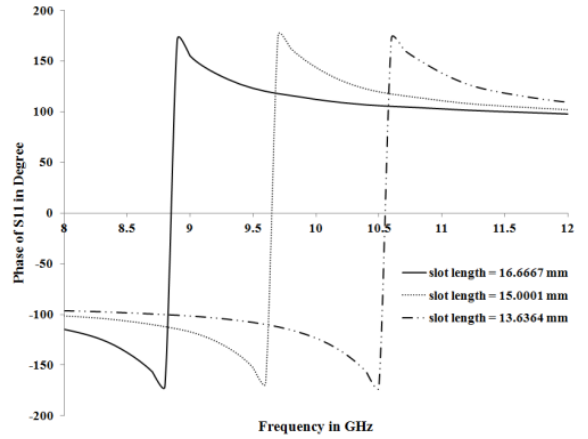

Figure 7: Variation of Complex Reflection Coefficients with Frequency for Two Broad Wall Longitudinal Slots Antenna System with Different Slot Length
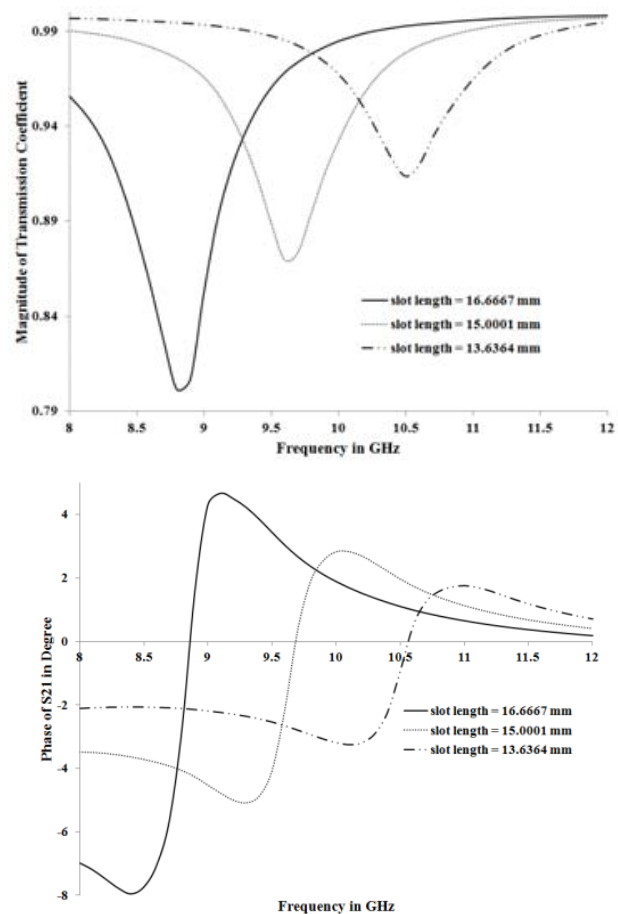

Figure 8: Variation of Complex Transmission Coefficients with Frequency for Two Broad Wall Longitudinal Slots Antenna System with Different Slot Length

The variation of the complex $\mathrm{S}$ - parameters for slots with for slot lengths $=16 \mathrm{~mm}$, thickness $=1.27 \mathrm{~mm}$, width $=1 \mathrm{~mm}$, $\mathrm{Xs}=2 \mathrm{~mm}, 4 \mathrm{~mm}, 6 \mathrm{~mm}, 8 \mathrm{~mm}, \mathrm{X}_{0}=-2 \mathrm{~mm},-4 \mathrm{~mm},-6$ $\mathrm{mm},-8 \mathrm{~mm},\left|\mathrm{X}_{\mathrm{Ws}}-\mathrm{X}_{\mathrm{WO}}\right|=24.13 \mathrm{~mm}$ and $\left|\mathrm{Z}_{\mathrm{Ws}}-\mathrm{Z}_{\mathrm{Wo}}\right|=24.1$ $\mathrm{mm}, 23.4 \mathrm{~mm}, 22.7 \mathrm{~mm}, 22.4 \mathrm{~mm}$ milled as a waveguide with $2 \mathrm{a}=22.86 \mathrm{~mm}, 2 \mathrm{~b}=10.16 \mathrm{~mm}$ are plotted with frequency in figure 9 and figure 10 respectively.

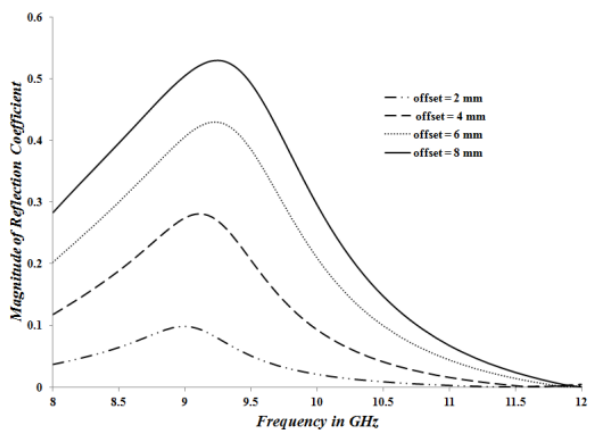




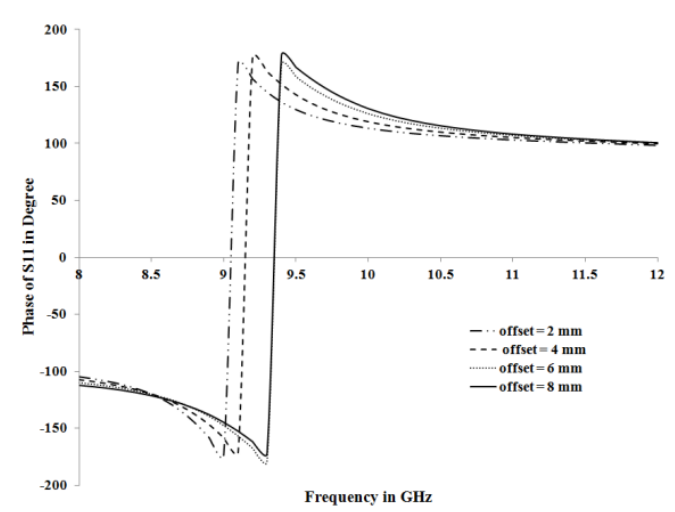

Figure 9: Variation of Complex Reflection Coefficients with Frequency for Two Broad Wall Longitudinal Slots Antenna System with Different Slot Offset
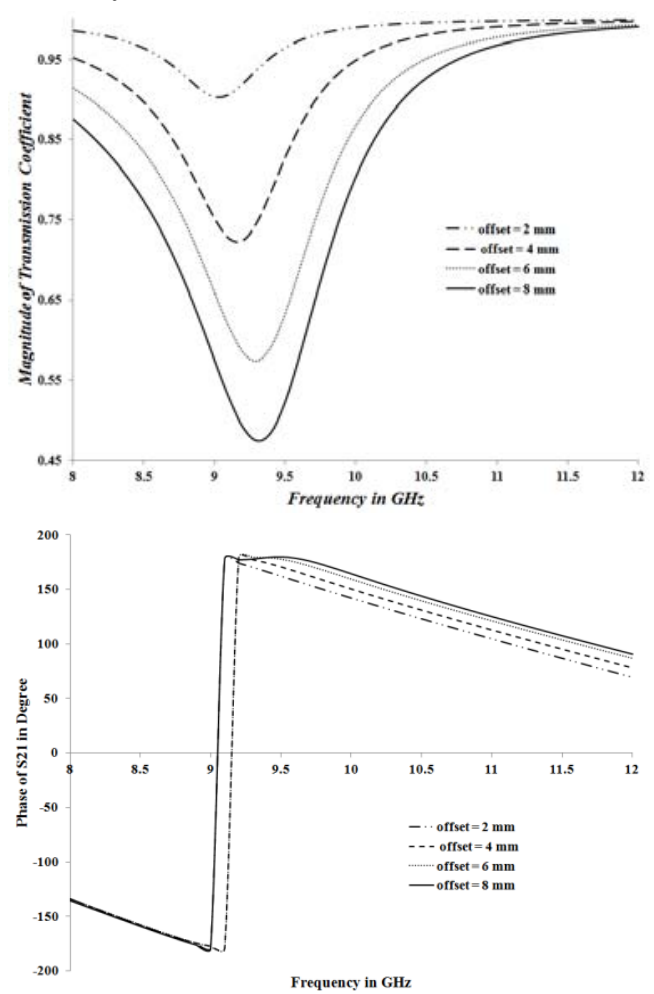

Figure 10: Variation of Complex Transmission Coefficients with Frequency for Two Broad Wall Longitudinal Slots Antenna System with Different Slot Offset

The variation of the complex $\mathrm{S}$ - parameters for slots with for slot lengths $=16.6667 \mathrm{~mm}, 15.0001 \mathrm{~mm}, 13.6364 \mathrm{~mm}$, thickness $=1.27 \mathrm{~mm}$, width $=1 \mathrm{~mm}, X_{\mathrm{S}}=4 \mathrm{~mm}, \mathrm{X} 0=4 \mathrm{~mm}$, $\left|\mathrm{X}_{\mathrm{Ws}}-\mathrm{X}_{\mathrm{W} 0}\right|=24.13 \mathrm{~mm}$ and $\left|\mathrm{Z}_{\mathrm{Ws}}-\mathrm{Z}_{\mathrm{wo}}\right|=23.4 \mathrm{~mm}$ milled as a waveguide with $2 \mathrm{a}=22.86 \mathrm{~mm}, 2 \mathrm{~b}=10.16 \mathrm{~mm}$ are plotted with frequency in figure 11 and figure 12 respectively.
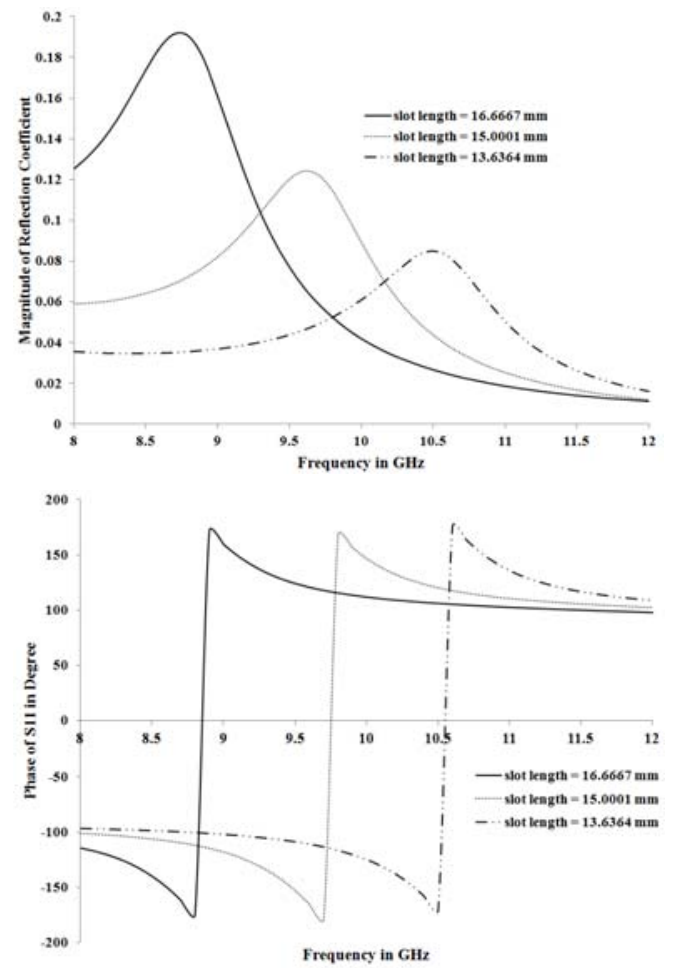

Figure 11: Variation of Complex Reflection Coefficients with Frequency for Two Broad Wall Longitudinal Slots Antenna System with Different Slot Length
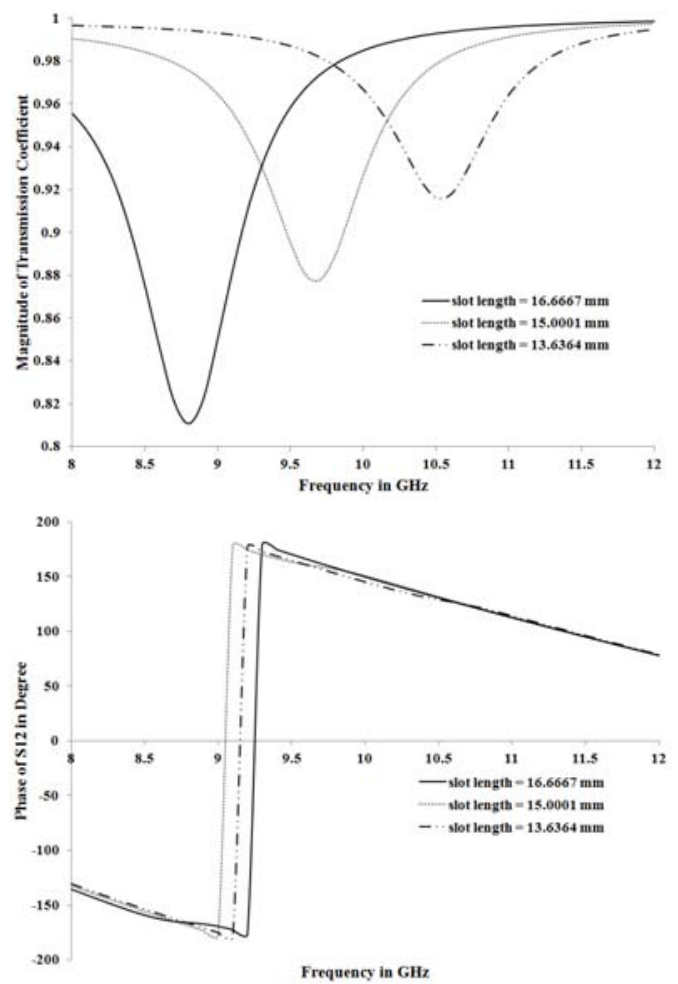

Figure 12: Variation of Complex Transmission Coefficients with Frequency for Two Broad Wall Longitudinal Slots Antenna System with Different Slot Length

The variation of resonant slot length and normalized resonant conductance for the proposed slot array with slot width $=1 \mathrm{~mm}$, thickness $=1.27 \mathrm{~mm}, \mathrm{X}_{\mathrm{s}}=4 \mathrm{~mm}, \mathrm{X}_{0}=-4 \mathrm{~mm}$, 
$\left|\mathrm{X}_{\mathrm{Ws}}-\mathrm{X}_{\mathrm{W} 0}\right|=24.13 \mathrm{~mm}$ and $\left|\mathrm{Z}_{\mathrm{Ws}}-\mathrm{Z}_{\mathrm{W} 0}\right|=0 \mathrm{~mm}$ milled as a waveguide with $2 \mathrm{a}=22.86 \mathrm{~mm}, 2 \mathrm{~b}=10.16 \mathrm{~mm} / 5.08 \mathrm{~mm}$ and $2.54 \mathrm{~mm}$ are plotted with frequency in figure 13 and figure 14 respectively.

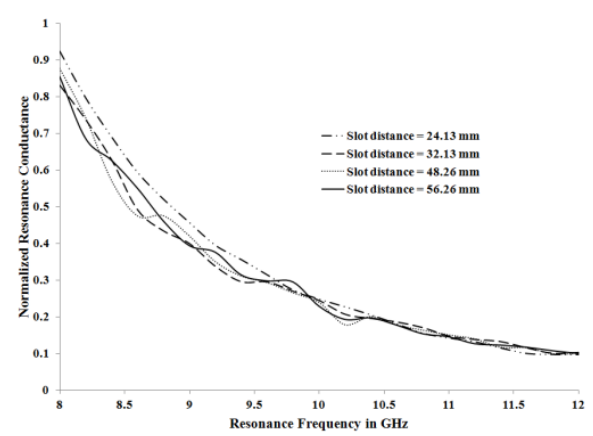

Figure 13: Variation of Resonant Length for the Proposed Slot Array Antennas Developed on Standard Waveguides over 8 to $12 \mathrm{GHz}$.

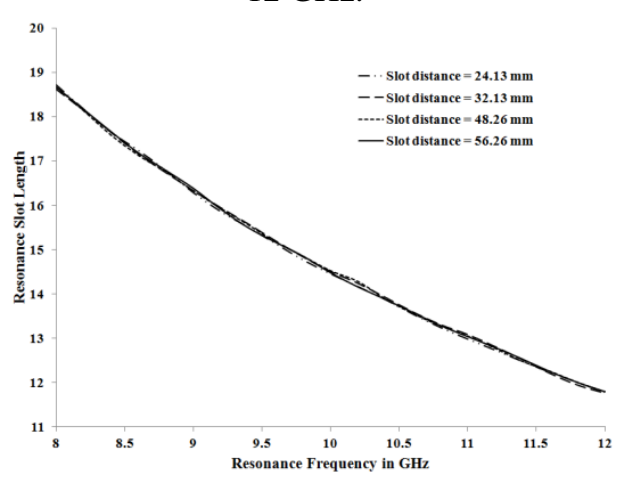

Figure 14: Variation of Normalized Conductance for the Proposed Slot Array Antennas Developed on Standard Waveguides over 8 to $12 \mathrm{GHz}$.

\section{CONCLUSION}

In this paper Multiple Cavity Modeling Technique (MCMT) has been applied to analyze a two element planer slot array antenna. Results have been validated by comparing with Ansoft HFSS's simulated data. The excellent agreement between these data validates the analysis. Slot resonance occurs at the frequency where phase of reflection and transmission coefficients become zero. It is evident from figure 5 and figure 6 that slots offset have no effect on resonance frequency. In fact slot offset is used to control the radiated power not the resonance frequency.

However, as evident from figure 7 - 8 and 11 - 12, when the slot length is increased, there is a decrease in the resonance frequency and which should be, because resonance length is of the order of half wavelength.

Figure 9 and 10 reveals thus, unlike $\left|X_{\mathrm{Ws}}-\mathrm{X}_{\mathrm{W} 0}\right|, \mid \mathrm{Z}_{\mathrm{Ws}}-$ $Z_{\mathrm{W} 0} \mid$ has a little effect on the resonance frequency and $\mid Z_{\mathrm{Ws}}-$ $\mathrm{Z}_{\mathrm{wo}}$ l decreased, the resonance frequency is decreased slightly.

It is evident from figure $13 \& 14$, the normalize resonance conductance depends on slot separation. The resonance slot length is independent of it. Therefore in a planner slot array interguide mutual coupling can affect the slot position not the slot length.

\section{REFERENCES}

[1] S. Gupta, Electromagnetic field estimation in aperture and slot Antennas with their equivalent network representation, Phd Dissertation, Department of Electronics \& Electrical Communication Engineering, I.I.T. Kharagpur, India, 1996.

[2] L.G. Josefsson, "Analysis of Longitudinal Slots in Rectangular Waveguide”, IEEE Trans. on Antennas and Propagation, Vol. AP-35, Pp. 1351-1357, Dec. 1987.

[3] R.W. Lyon and A.J. Sangster,"Efficient Moment Method Analysis of Radiating Slot in a Thick Walled Rectangular Waveguides”, IEE, Part H, Microwaves Opt. Antennas. Vol. 128, Pp. 197-205, August 1981.

[4] A.F. Stevenson, "Theory of slots in Rectangular Waveguides”, Journal of Applied Physics, Vol. 19, Pp. 24-38, Jan. 1948.

[5] A.B. Kakade and B. Ghosh, "Analysis of the rectangular waveguide slot coupled multilayer hemispherical dielectric resonator antenna”, IET Microw. Antennas Propag., Vol. 6, No. 3, Pp. 338-347, 2012.

[6] P.T. Benko, B.L. Turóczy and J. Pavo,” A Coupled Analytical-Finite Element Technique for the Calculation of Radiation From Tilted Rectangular Waveguide Slot Antennas”, IEEE Transactions on Magnetics, Vol. 44, No. 6, Pp 1666- 1669, June 2008.

[7] Y. Cong and W. Dou," Design of Dual-Polarized Waveguide Slotted Antenna Array for Ka-band Application”, Antennas Propagation and EM Theory (ISAPE), Pp. 97 - 100, 2010.

[8] B. Lai, X.W. Zhao, Z.J. Su, and C.H. Liang,” Higher-Order MoM Analysis of the Rectangular Waveguide Edge Slot Arrays", IEEE Transactions on Antennas and Propagation, Vol. 59, No. 11, November 2011.

[9] L. Jie, J. Yong-jin, Y. Chun-shan, S. Wen-feng,” Tolerance Analysis of Coupling Slot of Waveguide Slot Array”, Microwave, Antenna, Propagation and EMC Technologies for Wireless Communications, Pp. $647-650,2009$.

[10] A. Bastani and J. Rashed-Mohassed, "Analysis of Planar SlottedWaveguide Array Antennas with Longitudinal Slots using the Method of Moments”, IEEE Trans. Antennas Propagat., Vol. 1, Pp. 129-132, 2004.

[11] A.J. Sangstar, and H. Wang, "Resonance properties of omnidirectional slot doublet in rectangular waveguide,” Electronics Letters., Vol. 29, No. 1, Pp. 16 - 18, January 1993.

[12] A.J. Sangstar, and H. Wang, "Moment method analysis of a horizontally polarized omnidirectional slot array antenna,” Proc. of IEE Microwave Antenna Propagation., Vol. 142, No. 1, Pp. 1-6, February 1995.

[13] B.N. Das, and G.S. Sanyal., "Network Parameters Of A Waveguide Broad Wall Slot Radiator”, Proc. IEE, Vol.117, No.1, Pp.41 - 44, 1970.

[14] R.S. Elliott, “An improved design procedure for small arrays of shunt,” IEEE Trans. Antennas Propagat., Vol. AP-31, Pp. 48-53, jan. 1983.

[15] S. Das, Analysis of Rectangular waveguide based passive devices and antennas using Multiple cavity modeling technique, Phd Dissertation, Department of Electronics \& Electrical Communication Engineering, I.I.T. Kharagpur, India, 2007.

[16] R.F. Harrington, Field Computation By Moment Methods, Roger E. Krieger Publishing Company, USA, Pp. 5-7, 1993.

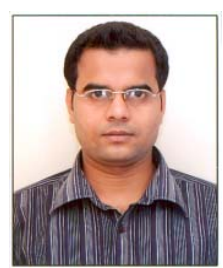

Rintu Kumar Gayen was born in Kharagpur, in the state of West Bengal. After doing his schooling at various places, he joined Birbhum Institute of Engineering and Technology in 2002, and completed Bachelor of Tech degree in 2006. Presently he is a Senior Research fellow in the Department of Electronics Engineering, Indian School of Mines Dhanbad.

In his area of specialization, he is interested in Electromagnetics, Antennas, and Microwave Circuits. He has published five papers in conferences. (Email:rintukrgayen@gmail.com)

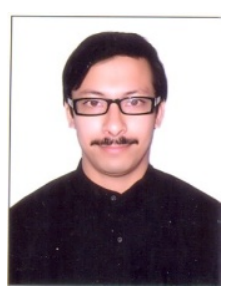

Sushrut Das was born in Serampore, in the state of West Bengal. After doing his schooling at various places, he joined Belur Ramakrishna Mission Vidyamandira in 1996, and completed Bachelor of Science degree in 1999 from the Department of Physics. He received Master of Science degree in Physics with specialization in Electronics from the Department of Physics, Banaras Hindu University in 2001. After completion of Master in Science Degree he joined 
Burdwan University and completed Master of Technology degree in Microwave in 2003 from the Department of Physics. He worked towards his doctoral degree till January, 2007 in the Department of Electronics and Electrical Communication Engineering, Indian Institute of Technology, Kharagpur. Presently he is working as an Assistant Professor in the Department of Electronics Engineering, Indian School of Mines - Dhanbad.

In his area of specialization, he is interested in Electromagnetics, Antennas, Microwave Circuits, Numerical Techniques in Electromagnetics and Electromagnetic Interference and Electromagnetic Compatibility. He has published thirty six papers in journals and conferences and presently is the

Principal Investigator of one DST sponsored project. (Email:sushrut_das@yahoo.com) 